\title{
Characterization and genus identification of the rhizobial symbiont from Caragana arborescens in Western Canada
}

\author{
Judicaël Moukoumi ${ }^{2}$, Russell K. Hynes ${ }^{1,4}$, Timothy J. Dumonceaux ${ }^{1}$, Jennifer Town ${ }^{1}$, \\ and Nicolas Bélanger ${ }^{3}$
}

\footnotetext{
${ }^{1}$ Agriculture and Agri-Food Canada, Saskatoon Research Centre, Saskatoon, SK;

${ }^{2}$ Department of Soil Science, University of Saskatchewan, Saskatoon, SK;

${ }^{3}$ Centre d'étude de la forêt, UER Science et technologie, Téluq, Université du Québec à Montréal, QC
}
${ }^{4}$ Corresponding author: Russell K. Hynes, Agriculture and Agri-Food Canada, Saskatoon
Research Centre, 107 Science Place, Saskatoon, SK, S7N OX2

Tel: 306-956-7638; Fax.: 306-956-7247

E-mail address: russell.hynes@agr.gc.ca

Sequences determined in this study were deposited into GenBank with the following accession numbers: for 16S: JF819654-JF819658; for recA: JF819659-JF819661; for cpn60: JF819662-JF81966 and KC521416-KC521435. 


\section{Abstract}

2 Naturally-occurring nitrogen-fixing symbionts from root nodules of caragana, (Caragana

3 arborescens), growing in central Saskatchewan were isolated following surface

4 sterilizing caragana root nodules, squashing and spreading the contents on yeast-extract

5 mannitol medium. The symbiotic nature of the strains was confirmed following

6 inoculation onto surface sterilized C. arborescens seed in a gnotobiotic Leonard jar

7 system. The Rhizobium isolates from C. arborescens root nodules are intermediate in

8 growth rate $(\mathrm{g})$ (mean of 5 isolates $\mathrm{g}=6.41$ ) as compared to fast growers, Rhizobium

9 leguminosarum NRG457 (g: 4.44), R. tropici 899 (g: 3.19) and Sinorhizobium meloliti

10 BALSAC (g: 3.45) but faster than the slow grower Bradyrhizobium japonicum USDA

11110 (g: 13.86) and similar to Mesorhizobium amorpheae (g: 7.76). Nitrogen derived from

12 fixation by measuring changes in $\delta^{15} \mathrm{~N}$ natural abundance in plant tissue confirmed the

13 effectiveness of the strains; approximately $80 \% \mathrm{~N}_{2}$ from fixation. Strain identification

14 was carried out by determining the sequences of three genes, 16S rRNA-encoding genes,

15 cpn60, and recA. This analysis determined that the symbiotic partner of Canadian $C$.

16 arborescens belong to genus Mesorhizobium and seem more related to $M$. loti than to

17 previously described Caragana symbionts like $M$. caraganae. This is the first report of

18 Mesorhizobium sp nodulating C. arborescens in western Canada.

19 Keywords: Mesorhizobium, Caragana arborescens, nitrogen fixation, cpn60 


\section{Introduction}

Caragana arborescens, commonly referred to as caragana or Siberian pea-shrub,

23 is a woody legume in the family Fabaceae and native to north-eastern Europe and central

24 Asia. Caragana arborescens was introduced to North America in 1752 and is the favored

25 species in western Canadian prairie for shelterbelts for seeded fields and farm homes

26 (Dietz et al. 2008). Its endurance to cold and drought conditions, long life span, ability to

27 fix nitrogen, and height of 4-5 m made it an acceptable choice. C. arborescens tolerance

28 to cold was reported by Hensley and Carpenter (1979). The lowest activation temperature

29 of nodules from the several legumes tested were those of $C$. arborescens, i.e. $3-5^{\circ} \mathrm{C}$.

30 Symbiotic interactions involving leguminous plants and rhizobia result in the

31 differentiation of root or stem tissue into nodules where these bacteria reduce nitrogen

32 gas to nitrogenous compounds which enter the plant's metabolic machinery. Early studies

33 by Beijerinck suggested that the root nodule isolates from C. arborescens were similar to

34 the slow growing rhizobia from cowpea, soybean or lupin (Allen and Allen 1939).

35 Gregory and Allen (1953) reported markedly different growth rates and other

36 physiological differences from fourteen rhizobial isolates from root nodules of $C$.

37 arborescens. Plant cross-inoculation groupings placed the rhizobia that nodulate $C$.

38 arborescens in the Lotus group (Jarvis et al. 1982). Further refinements in the

39 nomenclature of Rhizobium spp. resulted in the transfer of the C. arborescens symbiont to

40 Mesorhizobium gen nov (Jarvis et al. 1997). In a phylogenetic tree based on the $16 \mathrm{~S}$

41 rRNA-encoding gene, Chen et al. (2008) reported that Mesorhizobium sp CCBAU 11226,

42 isolated from C. arborescens roots, was closely-related to M. tianshanense USDA 3592

43 (>99.3\% sequence identity at the $16 \mathrm{~S}$ rRNA-encoding locus). To our knowledge, the 
44 identity of the rhizobia species nodulating $C$. arborescens in Canada has not been studied

45 or reported.

46 In 2007, field plots were established in Saskatchewan, Canada, with pure and

47 mixed plantations of willow (Salix miyabeana) and C. arborescens, to examine the

48 potential of species association as a strategy for sustained productivity and reduced $\mathrm{CO}_{2}$

49 footprint (Moukoumi et al. 2012). Examination of field grown C. arborescens revealed

50 that the roots were nodulated, whereas it was determined with the $\delta^{15} \mathrm{~N}$ natural abundance

51 method that as much as $30 \%$ of total nitrogen in C. arborescens leaves on poor soils

52 originated from the atmosphere (i.e. $\mathrm{N}$ obtained from biological $\mathrm{N}_{2}$-fixation). These

53 results suggest that the soil had a competent population of rhizobia. The objectives of this

54 study were to: 1) isolate naturally occurring nitrogen-fixing symbionts from $C$.

55 arborescens root nodules, 2) confirm $\mathrm{N}_{2}$ fixation activity by the $\delta^{15} \mathrm{~N}$ natural abundance

56 method, and 3) apply $16 \mathrm{~S}$ rRNA, recA, and cpn60 sequence analysis to identify the

57 rhizobial symbiont from $C$. arborescens.

58 Materials and methods

59 Isolation of putative Rhizobium strains from C. arborescens root nodules

60 Nodules were collected from the roots of $C$. arborescens plants carefully

61 extracted from field plots in three former agricultural fields in central Saskatchewan; two

62 associated with the University of Saskatchewan, Saskatoon and a third in Harris, Sk, 90

$63 \mathrm{~km}$ southwest of Saskatoon. Field site characteristics are reported in Moukoumi et al.

64 (2012). Thirty root nodules were surface sterilized by immersing and with shaking in

$6595 \%$ ethanol for $20 \mathrm{sec}, 5 \mathrm{~min}$ in $20 \%$ sodium hypochlorite (commercial Clorox bleach

66 diluted $5 \times$ in sterile $\mathrm{dH}_{2} \mathrm{O}$ ) and rinsed 7 times in sterile $\mathrm{dH}_{2} \mathrm{O}$. Surface sterilized nodules 
67 were squashed, using flame-sterilized forceps, and the nodule contents were spread over

68 the surface of yeast extract-mannitol agar (YMA); g/1000mL dH $\mathrm{m}_{2}$ : mannitol, 10;

$69 \mathrm{~K}_{2} \mathrm{HPO}_{4}, 0.5 ; \mathrm{MgSO}_{4} .7 \mathrm{H}_{2} \mathrm{O}, 0.2 ; \mathrm{NaCl}, 0.1 ; \mathrm{CaCO}_{3}, 0.01$; yeast extract (Difco, Detroit)

70 0.5; agar, $15 \mathrm{~g}$, in Petri dishes and incubated at $23{ }^{\circ} \mathrm{C}$ (Weaver and Frederick 1982). After

$714 \mathrm{~d}$ colonies of putative Rhizobium strains were restreaked on YMA and incubated at

$7223^{\circ} \mathrm{C}$. This process was repeated 2 additional times to insure purity before inoculating

73 YM broth (Weaver and Frederick 1982). After 4 days of incubation with shaking at 150

$74 \mathrm{rpm}$ at $23{ }^{\circ} \mathrm{C}$, the cultures were streaked onto YMA and nutrient agar (Difco, Detroit) for

75 additional purity checks. Five putative isolates named Laura, Harris, Sovereign, Thrasher

76 and Kernan were retained and preserved in a $-80{ }^{\circ} \mathrm{C}$ freezer.

77 Generation time (g) studies - comparison to reference Rhizobiaceae isolates

78 One hundred $\mathrm{mL}$ of YM broth in $250 \mathrm{~mL}$ baffled flasks was inoculated with 0.2

$79 \mathrm{~mL}$ of stationary phase cultures of each isolate and reference isolates from other genera

80 of rhizobia. All isolates were incubated at $23^{\circ} \mathrm{C}$ with shaking at $150 \mathrm{rpm}$. Population

81 densities of rhizobial isolates Laura, Harris, Sovereign, Thrasher and Kernan,

82 Sinorhizobium meloliti BALSAC, Rhizobium leguminosarun NRG457 (Agriculture Agri-

83 Food Canada), R. tropici 899, a.k.a. CIAT899 (University of Minnesota),

84 Bradyrhizobium japonicum USDA 110 (kindly provided by Guoping Yang,

85 BeckerUnderwood Inc.), and M. amorpheae (DSM No. 21831) were determined by serial

86 dilution and plating on YMA. Generation time (g) was determined by first calculating the

87 number of generations (n) that occurred during the logarithmic phase of growth ( $\mathrm{N}$ and

88 No: final and original population densities) from the equations:

89

$$
\mathrm{n}=\left(\log _{10} \mathrm{~N}-\log _{10} \mathrm{No}\right) / \log _{10} 2
$$


90 Generation time was calculated from the equation: $\mathrm{g}=\mathrm{t} / \mathrm{n}$

91 where $\mathrm{t}$ is elapsed time from $\mathrm{N}$ and No. Mean generation times were calculated from

92 triplicated growth experiments with each isolate.

\section{$93 \quad$ Leonard jar studies}

94 C. arborescens seeds, provided by the Agroforestry Development Centre (Indian

95 Head, Sk.), were surface sterilized using a 95\% ethanol solution for $25 \mathrm{sec}$ followed by a

$9620 \%$ sodium hypochlorite (as above) solution for $20 \mathrm{~min}$. Following 7 sterile $\mathrm{dH}_{2} \mathrm{O}$

97 rinses, the seed was placed in a laminar flow hood to dry. The seeds were then pre-

98 germinated on moistened sterile filter paper and two seedlings were later transplanted

99 into sterilized Leonard jar assemblies (Vincent 1970). The upper part of the assembly,

$100300 \mathrm{~mL}$, was filled with acid washed sand and the lower part of the assembly, $500 \mathrm{~mL}$,

101 contained N-free plant nutrient solution (Hoagland and Arnon 1950). Putative Rhizobium

102 isolates grown in YM broth and incubated on a reciprocal shaker $(150 \mathrm{rpm})$ at $23^{\circ} \mathrm{C}$ for 4

103 days were applied in $1 \mathrm{~mL}$ aliquots to each seedling. Treatments included $C$. arborescens

104 seedlings inoculated individually with strains Laura, Harris, Sovereign, Thrasher and

105 Kernan and the non-inoculated control. C. arborescens was grown in a Conviron plant

106 growth room with day/night temperatures of 23 and $20^{\circ} \mathrm{C}$ and 10 hours of light and 14

107 hours of darkness. After 90 days, C. arborescens shoots were cut from the roots, dried at

$10865^{\circ} \mathrm{C}$ for 3 days, weighed and finely ground before ${ }^{15} \mathrm{~N} /{ }^{14} \mathrm{~N}$ and total $\mathrm{C}$ and $\mathrm{N}$ analysis.

109 Foliage sampling and analyses of nitrogen $(\mathbf{N})$, carbon $(\mathbf{C})$ and $\mathbf{N}$ isotopes

110 The oven-dried samples were coarsely ground prior to leaf $\mathrm{N}$ and $\mathrm{C}$ determination

111 by dry combustion and infrared detection using a Leco CNS 2000 Analyzer (LECO

112 Corporation, St. Joseph, MI). Sub-samples were then further ground $(<60 \mu \mathrm{m})$ and $1.0 \pm$ 
$1130.15 \mathrm{mg}$ was analyzed for ${ }^{15} \mathrm{~N} /{ }^{14} \mathrm{~N}$ ratios using a continuous flow isotope ratio mass

114 spectrometer interfaced with a RoboPrep Sample Converter (Europa Scientific, Crewe,

115 UK). The working standard for ${ }^{15} \mathrm{~N} /{ }^{14} \mathrm{~N}$ was pea grain $\left(\right.$ atom $\%{ }^{15} \mathrm{~N}$ content $=0.36726$ ).

116 The deviation of the sample ${ }^{15} \mathrm{~N} /{ }^{14} \mathrm{~N}$ ratio from that of the atmosphere $\left(\delta^{15} \mathrm{~N}\right)$ was

117 calculated as follows:

$$
\delta^{15} N=\left(\left(R_{\text {sample }} / R_{\text {standard }}\right)-1\right) \times 1000
$$

\section{Molecular phylogenetic studies of the putative Rhizobium strains}

DNA was extracted from $200 \mu \mathrm{L}$ of an overnight culture of each isolate using a

122 modified bead-beating protocol as described by Hill et al. (2005a). Final DNA pellets

123 were dissolved in $100 \mu \mathrm{L}$ of $10 \mathrm{mM}$ Tris-Cl pH 8.0 with $1 \mathrm{mM}$ EDTA. Two $\mu \mathrm{L}$ of each

124 extract were used as a template in a PCR with primers F1 and R2 (Dorsch and

125 Stackebrandt 1992), which amplify nucleotides $11-536$ of the 16S rRNA-encoding gene

126 (numbering according to $E$. coli sequence). $r e c A$ gene fragments were amplified using

127 primers recA63F and recA555R as described by Gaunt et al. (2001). 16S rRNA and recA

128 amplicons were sequenced directly using the amplification primers. For amplification of

129 the cpn60 universal target (cpn60 UT) (Hill et al. 2004), a cocktail of primers H279/H280

130 and H1612/H1613 was used as described (Hill et al. 2005b) with an annealing

131 temperature of $50^{\circ} \mathrm{C}$. Amplicons were generated using combinatorial enhancer solution

132 (CES) according to Ralser et al. (2006) in order to improve the representation of all

133 copies of cpn60 from each isolate. cpn60 UT PCR products were ligated into pGEM-T

134 Easy PCR product cloning vector (Promega, Madison, WI) according to the

135 manufacturer's directions prior to sequencing, and a total of 48 cpn60 UT clones was 
136 sequenced for each isolate. Sequences were analyzed using pregap v1.5/gap v4.10

137 (Staden package) to generate contigs that were manually checked for quality and trimmed

138 of primer sequences.

139 Taxonomic analysis. $16 \mathrm{~S}$ rRNA, recA, and cpn60 UT sequences were aligned using the

140 default parameters of clustalw (Thompson et al. 1994) to determine sequence identities.

141 Phylogenetic analysis was performed using the neighbor joining method (Saitou at al.

142 1987) with bootstrapping using 500 replicates. Phylogenetic trees were generated using

143 MEGA4 (Tamura et al. 2007).

144 Whole-genome alignments and determination of average nucleotide identity (ANI) by

145 MumMer (ANIm), ANI by BLAST (ANIb), and tetranucleotide frequency correlations

146 (Tetra) were determined using JSpecies as described by Richter and Rossello-Mora

147 (2009). Mesorhizobium genomic sequences were obtained from NCBI (M. ciceri biovar

148 biserrulae WSM1271, M. australicum WSM2073, M. opportunistum WSM2075, and M.

149 loti MAFF303099) or from the Joint Genome Initiative Genome Portal

150 (http://genome.jgi-psf.org/) for M. loti WSM1293, M. loti R7A, M. loti R88b, M. loti

151 NZP2037, M. loti R7A, and Mesorhizobium sp. BNC1. Sequences of all cpn60 UT copies

152 that were not available in GenBank or in $\mathrm{cpnDB}$ were retrieved from the draft genomes

153 using BLASTp with the M. loti cpn60 UT peptide sequence (cpnDB ID b4797) as the

154 query.

\section{Data analysis}

156 Means of triplicate samples of each treatment plus/minus standard errors are

157 reported.

158 Results 
161 streaked with the contents from squashed root nodules of $C$. arborescens. Visual

162 characterization of the five putative isolates of Rhizobium was as follows: colonies were

163 opaque white, raised and round and 0.5 to $1 \mathrm{~mm}$ in diameter after 6 days growth at $23^{\circ} \mathrm{C}$.

164 Generation time (g) studies - comparison to reference Rhizobiaceae isolates

Generation times $(\mathrm{g})$ of the five rhizobia isolates were compared to fast,

166 intermediate and slow growing Rhizobiaceae isolates (Table 1). The isolates from $C$.

167 arborescens root nodules were intermediate in growth rate as compared to the fast

168 growing $R$. leguminosarum NRG457, g: 4.44; R. tropici 899, g: 3.19 and S. meloti

169 BALSAC, g: 3.45 and slow growing B. japonicum USDA110, g: 13.86 (Table 1). The

170 mean $\mathrm{g}$ for the $C$. arborescens root nodules isolates was 6.41, similar to that of an

171 intermediate growing $M$. amorpheae, g: 7.76. Acid production by the $C$. arborescens root

172 nodules isolates, $S$. meloliti BALSAC, R. tropici 899, R. leguminosarum NRG457 and

173 alkali production by B. japonicum USDA 110 in YM broth were noted (data not

174 presented).

175 Leonard jar studies

176 Nodules with red interiors developed on C. arborescens roots, indicative of the

177 presence of leghemoglobin and effective nitrogen-fixing activity. C. arborescens root

178 nodules were elongate, approximately 3 by $1.5 \mathrm{~mm}$ and typically there were $20-30$

179 nodules per plant. All inoculated plants growing in a $\mathrm{N}$-free medium (Hoagland and

180 Arnon 1950) had dark green leaves, suggesting that these plants were supplied $\mathrm{N}$ by

181 symbiotic nitrogen fixation. Non-inoculated C. arborescens plants displayed stunted 
182 growth, the roots did not have nodules and the leaves were yellow, indicative of $\mathrm{N}$

183 deprivation.

184 Nitrogen and $\mathrm{C}$ concentrations and $\mathrm{N}$ isotopes data generated from the leaves

185 collected from the nodulated and non-nodulated C. arborescens are presented in Table 2.

186 Nodulated plants had on average 4.9 and 3.2 times higher percent $\mathrm{N}$ and $\mathrm{C}$ than the non-

187 nodulated (non-inoculated) plants (Table 2). $\delta^{15} \mathrm{~N}$ varied from -1.84 to -1.44 for the

188 nodulated plants. $\delta^{15} \mathrm{~N}$ of the non-inoculated plants was 0.8 indicative that all of the $\mathrm{N}$

189 was derived from the seed.

190 Molecular taxonomic studies of the putative Rhizobium strains

191 Comparison of the 16S rRNA-encoding genes of the five isolates to the

192 corresponding reference strains suggested that the isolates formed two groups within the

193 genus Mesorhizobium (Figure 1). The 16S rRNA-encoding sequences of isolates Laura

194 and Kernan were closely related to M. amorphae, M. australicum and Mesorhizobium

195 isolates CCBAU 11231, CCBAU 11214, and CCBAU 11208 identified by Chen et al.

196 (2008). Isolates Harris, Sovereign and Thrasher had identical 16S rRNA-encoding

197 sequences that were closely related to a group of Mesorhizobium spp. including $M$.

198 caraganae, M. loti, and CCBAU 11226 (Chen et al. 2008). Although the 16S rRNA-

199 encoding sequences of all the isolates and reference strains formed distinct clustering

200 patterns that were consistent with those described by Chen et al. (2008), the sequences

201 were highly similar to one another, sharing sequence identities > 97\% (data not shown).

202 We also examined two protein-encoding genes, cpn60 and recA, for determining

203 the taxonomic affiliations of the isolates. Since cpn60 is present in multiple copies in the

204 root-nodulating Alphaproteobacteria (Lund 2009), we examined all of the currently 
205 available complete genomes for Mesorhizobium spp. Representative results are shown in

206 Table 3. Determination of the genomic identity parameters described by Richter and

207 Rossello-Mora (2009) revealed that most of these sequenced strains can be identified as

208 separate species, consistent with their current taxonomic designations, although their

209 close phylogenetic relationship is reflected in the generally high Tetra scores that were

210 observed (Table 3). Among the 5 M. loti genomes that were compared, however, only

211 one pair, M. loti MAFF303099 and M. loti R7A, had sufficiently similar genomic

212 sequences to be considered the same species according to the metrics suggested by

213 Richter and Rossello-Mora (2009) (Table 3). Turner et al. (2002) suggested that strain

214 MAFF303099 has been mis-assigned to $M$. loti and should instead be classified as $M$.

215 huakuii biovar loti. Unfortunately the lack of a complete genome sequence for the latter

216 strain precludes its inclusion in this whole-genome sequence analysis. All of the other

217 pairs of $M$. loti genomes fell below the sequence similarity cutoffs defined by Richter and

218 Rossello-Mora (2009) for grouping into the same species (Table 3 and data not shown).

219 Among all of the strains, the number of copies of cpn60 varied, from as few as 2 copies

220 in Mesorhizobium spp. BNC1 to as many as 5 in M. loti MAFF303099. Some of these

221 copies shared a very high sequence identity (up to 1.0), despite being from distinct

222 species as shown by JSpecies (Table 3). Other cpn60 copies were highly distinct from

223 one another, with pairwise cpn60 UT sequence identities of 0.74-0.76.

224 Clones corresponding to the cpn60 UT were retrieved for all isolates. The number

225 of distinct cpn60 copies that were retrieved for each isolate varied from 3 (isolate

226 Sovereign) to 7 (isolate Thrasher) (Table 4). In all cases, the cpn60 copies from a single

227 isolate were most closely related to 2 or 3 different Mesorhizobium spp., with sequence 
228 identities ranging from $87.2 \%$ to $98.7 \%$ (Table 4). Phylogenetic analysis of all of the

229 cpn60 copies observed from all isolates revealed that several of the cpn60 sequences from

230 the isolates were identical or nearly identical to one another (supplemental Figure $1^{1}$ ).

231 Only one cpn60 sequence was observed in all of the strains (Sovereign cpn60-2, Laura

232 cpn60-4, Harris cpn60-3, Thrasher cpn60-2, Kernan cpn60-2) This cpn60 sequence

233 shared $~ 94 \%$ sequence identity with 3 of the cpn60 copies from M. loti MAFF303099. A

234 few other cpn60 sequences were shared by 2 or 3 isolates (supplemental Figure $1^{1}$ ).

235 Generally the cpn60 sequences of the C. arborescens-nodulating isolates described here

236 tended to cluster together (Supplemental Figure $1^{1}$ ).

237 Finally, to place these isolates in the context of reference strains of

238 Mesorhizobium as well as the isolates reported by Chen et al. (2008) and Yan et al.

239 (2007) the sequences of $r e c A$ fragments for isolates Sovereign, Thrasher and Kernan were

240 determined. These sequences were all identical to one another and phylogenetic analysis

241 placed these isolates in a clade with M. loti LMG 6125 as well as M. ciceri (Figure 2).

242 The isolates reported here appeared to be distinct from the strains isolated by Chen et al.

243 that form a symbiotic relationship with $C$. arborescens (Chen et al. 2008, Yan et al.

244 2007).

\section{Discussion}

246 Mesorhizobium isolates were collected from C. arborescens root nodules grown

247 in soil containing naturally occurring and effective rhizobia. This study is part of a larger

248 study examining species association and nitrogen contribution from $\mathrm{N}$-fixing $C$.

249 arborescens to Salix miyabeana (Moukoumi et al. 2012). Wind carrying soil laden with

\footnotetext{
${ }^{1}$ Supplemental data are available with this article through the journal web site at
} 
250 effective rhizobia for caragana from near-by ( $2 \mathrm{~km}$ or more) rows of caragana is the

251 likely source of inoculum since these agricultural sites had never been planted with

252 caragana. The origin of this rhizobial population is unknown, but presumably was

253 introduced to Saskatchewan soils from northern Asia with C. arborescens over 1 century

254 ago (Cram 1969). The importance of an effective rhizobial symbiont for survival and

255 establishment of $C$. arborescens was highlighted when $C$. arborescens was introduced in

256 New Zealand for revegetation of semiarid areas (Wills 1982). Nodulated by ineffective

257 rhizobia, C. arborescens was chlorotic, slow to establish and displayed low survival rates

258 (Wills 1982). The long history of cultivating C. arborescens in Saskatchewan to mitigate

259 wind erosion of soils has resulted in the soil becoming enriched with effective rhizobial

260 symbionts. Indeed, Vlassak et al. (1973) reported in a Saskatchewan field study using the

261 acetylene reduction technique that $C$. arborescens fixed $335 \mu \mathrm{g} \mathrm{N} / \mathrm{g}$ soil $/ \mathrm{h}$. In the present

262 study, the contribution of fixed nitrogen and identity of the rhizobial symbiont of $C$.

263 arborescens growing in western Canada was determined by $\delta^{15} \mathrm{~N}$ natural abundance

264 method and sequence analysis of selected genes.

265 Mesorhizobium spp. from this study exhibited an intermediate growth rate (g)

266 similar to that described of other rhizobia isolated from $C$. arborescens root nodules from

267 diverse locations and similar to Mesorhizobium amorpheae; slower than, for example,

268 Rhizobium leguminosarum NRG457, R. tropici 899 and Sinorhizobium meloliti

269 BALSAC, but faster than Bradyrhizobium japonicum USDA 110 (Gregory and Allen

270 1953, Jarvis et al. 1982, Willems, 2006). Mesorhizobium spp. from this study formed

271 effective nodules on C. arborescens roots and augmented the allocation of $\mathrm{N}$ into the

272 leaves in a gnotobiotic system (Vincent 1970). 
Plant tissue from C. arborescens inoculated with isolates Laura, Harris,

274 Sovereign, Thrasher and Kernan had much higher total $\mathrm{N}$ content and a negative $\delta^{15} \mathrm{~N}$

275 signal indicative of effective symbiotic $\mathrm{N}_{2}$ fixation. The ${ }^{15} \mathrm{~N}$ natural abundance method is

276 based on the premise that plants that do not fix atmospheric $\mathrm{N}_{2}$ have a positive ${ }^{15} \mathrm{~N}$

277 content while $\mathrm{N}_{2}$-fixing plants have a lower or negative ${ }^{15} \mathrm{~N}$ content. Non-fixing plants

278 extract soil $\mathrm{N}$ in the form of $\mathrm{NH}_{4}{ }^{+}$and $\mathrm{NO}_{3}{ }^{-}$(high ${ }^{15} \mathrm{~N}$ content) while $\mathrm{N}_{2}$-fixing plants rely

279 on atmospheric $\mathrm{N}_{2}$ (low ${ }^{15} \mathrm{~N}$ content). Consequently, non-fixing plants have positive $\delta^{15} \mathrm{~N}$

280 content and $\mathrm{N}_{2}$-fixing plants dilute the $\delta^{15} \mathrm{~N}$, yielding negative $\delta{ }^{15} \mathrm{~N}$ content (Galiana et

281 al. 2002).

282 Jensen (1967) reported rhizobia that nodulated Lotus spp. formed a cross-

283 inoculation group that included several other legumes including C. arborescens. The new

284 species, Rhizobium loti that formed nodules on C. arborescens, first appeared in Bergey's

285 Manual of Systematic Bacteriology Volume 1 in 1984 but was later transferred to the

286 new genus, Mesorhizobium (Jarvis et al. 1997). Mesorhizobium spp. have been identified

287 by $16 \mathrm{~S}$ rRNA gene sequence analysis as being responsible for forming nodules on $C$.

288 arborescens in China and Russia (Chen et al. 2008, Baymiev et al. 2010).

289 Determination of the $16 \mathrm{~S}$ rRNA-encoding sequences of the isolates revealed

290 clustering patterns that were consistent with those reported by Chen et al. (2008), with

291 isolates Laura and Kernan apparently more similar to M. amorphae and M. australicum,

292 and the other isolates clustering with a number of different Mesorhizobium spp. that have

293 been reported to nodulate $C$. arborescens, including M. caraganae (Guan et al. 2008) and

294 Mesorhizbium spp. CCBAU 11226 (Chen et al 2008). These results suggested that the 
295 isolates represented two groups of strains, but the high level of sequence conservation at

296 the 16S locus among these strains made it difficult to discern their taxonomic relatedness.

297 Since the high similarity of the 16S rRNA-encoding sequences of the isolates

298 and reference strains made it difficult to determine the taxonomic assignment of the

299 isolates, two protein-encoding genes were examined. The 555 nucleotide (185 amino

300 acid) cpn60 UT can predict taxonomic assignments using a genomic sequence identity

301 prediction model (Verbeke et al. 2011) and has been proposed as a DNA barcode marker

302 for Bacteria due to its high sequence diversity and barcode gap compared to 16S rRNA-

303 encoding genes (Links et al. 2012). Furthermore, cpn60 UT sequences can be compared

304 to cpnDB, a publicly available database of cpn60 UT sequences (www.cpndb.ca; Hill et

305 al. 2004). Despite these advantages, Mesorhizobium spp. and other root-nodulating

306 Alphaproteobacteria harbor multiple, distinct copies of the cpn60 gene, some of which

307 are thought to play a role in the root-nodulating phenotype (Lund 2009, Shimoda et al.

308 2008, Okubo et al. 2012, Wallington and Lund 1994). This has the potential to

309 complicate the assignment of taxonomic identities using cpn60 gene sequences since

310 gene transfer events among otherwise distinct species that have similar functional roles

311 may occur. We therefore compared the cpn60 UT sequences for each of the reference

312 strains for which all copies of cpn60 are known. This analysis revealed that certain cpn60

313 copies shared very high sequence identities among demonstrably distinct species of

314 Mesorhizobium (Table 3), which may indeed reflect relatively recent horizontal gene

315 transfer events. However, we could find no evidence in cpnDB that any of these

316 sequences were found in any genus besides Mesorhizobium spp., which suggests that

317 such gene transfer events may be restricted to taxonomically closely related 
318 Mesorhizobium spp. The cpn60 UT may therefore be useful as a taxonomic marker for

319 Mesorhizobium spp., but it seems unable to resolve below the genus level in this case,

320 unlike for most other taxonomic groups (Links et al. 2012). This is likely true of other

321 root-nodulating Alphaproteobacteria as well.

322 Comparing the cpn60 UT sequences of the isolates to one another and to

323 reference sequences revealed that the various cpn60 copies of the isolates tended to

324 cluster together, with several cases of identical cpn60 UT sequences coming from

325 different isolates. Notably, one sequence was shared in all 5 of the isolates (supplemental

326 Figure 1) which was most closely related (94\% sequence identity) to one of the cpn60

327 genes of M. loti MAFF303099 (cpnDB ID b1085). It is possible that this copy of cpn60

328 plays a role in the nodulation host range of these isolates, since they were found in

329 distinct geographic regions of Saskatchewan but nodulate the same plant species.

$330 \quad$ recA has been examined as a sequence that could be used to predict genomic

331 sequence identity (Zeigler 2003), and has been shown to display similar phylogenies to

332 the 16S rRNA-encoding gene for root-nodulating Alphaproteobacteria with somewhat

333 higher sequence divergence (Gaunt et al. 2001). recA analysis indicated that isolates

334 Sovereign, Thrasher and Kernan form a group with $M$. loti and M. ciceri and are

335 apparently distinct from the Chinese isolates reported by Chen et al. (2008) and Yan et al.

336 (2007). Consistent with this, isolates Sovereign and Thrasher also had identical 16S

337 rRNA-encoding gene fragments. However, while recA is typically a better predictor of

338 species assignment than 16S rRNA-encoding genes (Ziegler 2003), the 16S rRNA-

339 encoding gene fragment of isolate Kernan was only $98 \%$ identical to the $r e c A$ gene

340 fragment of isolates Sovereign and Thrasher (Figure 1 and 2). This discrepancy could be 
341 due to the fact that full-length $\operatorname{rec} A$ genes were not determined in this study. Altogether,

342 molecular taxonomic analysis using the 3 genes investigated consistently placed all of the

343 isolates within the genus Mesorhizobium, although none of the three markers was able to

344 conclusively assign these isolates to a known species. These results underscore the

345 difficulties in assigning taxonomic identities to Mesorhizobium spp., even with whole

346 genome sequences available (Sahgal and Johri 2006). It is likely that the determination

347 of the whole or partial genomic sequences of the isolates as suggested by Richter and

348 Rossello-Mora (2009) would help to resolve this.

\section{Acknowledgements}

350 This project is supported by the Saskatchewan Ministry of Agriculture Strategic

351 Research Program: Soils and Environment-Soil Biological Processes and in part by a

352 NSERC Strategic Project Grant. We thank Dr.'s Richard Farrell, Department of Soil

353 Science, University of Saskatchewan for his contributions to N dynamics, including ${ }^{15} \mathrm{~N}$

354 natural abundance work in this study and S. Hemmingsen, NRC-Plant Biotechnology

355 Institute for assistance with DNA sequencing. This manuscript is dedicated to the late Dr.

356 Peter Graham who provided the inspiration to complete this work. 


\section{References}

Allen, O.N. and Allen, E.K. 1939. Root nodule bacteria of some tropical leguminous plants. Soil Sci. 47: 63-76.

Baymiev, A.K., Ptitsyn, K.G., and Baimiev, A.K. 2010. Influence of the introduction of Caragana arborescens on the composition of its root-nodule bacteria.

$$
\text { Microbiology 79: 115-120. }
$$

Chen, W.F., Guan, S.H., Zhao, C.T., Yan, X.R., Man, C.X., Wang, E.T., and Chen, W.X. 2008. Different Mesorhizobium species associated with Caragana symbiotic genes and have common host ranges. FEMS Microbiol Lett 283: 203-209.

Cram, W.H. 1969. Breeding and genetics of caragana. The Forestry Chronicle 45: 400401.

Dietz, D.R., Slabaugh, P.E. and Bonner, F.T. 2008. Caragana arborescens Lam. In The Woody Plant Seed Manual, Agriculture Handbook No. 727, Edited by F. T. Bonner and R. P. Karrfalt. U.S. Department of Agriculture, Forest Service, Washington, DC. pp. 321-323.

Dorsch, M., and Stackebrandt, E. 1992. Some modifications in the procedure of direct sequencing of PCR amplified 16S rDNA. J. Microbiol. Meth. 16: 271-279.

Galiana A., Balle P., Kang, A.N., Domenach, A,M. 2002. Nitrogen fixation estimated by the $15 \mathrm{~N}$ natural abundance method in Acacia mangium Willd. inoculated with Bradyrhizobium sp. and grown in silvicultural conditions. Soil Biol. Biochem. 34: $251-262$. 
Gaunt, M. W., Turner, S. L., Rigottier-Gois, L., Lloyd-Macgilp, S. A. and Young, J. P. 2001. Phylogenies of atpD and recA support the small subunit rRNA-based classification of rhizobia. Int. J. Syst. Evol. Microbiol. 51: 2037-2048.

Gregory, K.F. and Allen, O.N. 1953. Physiological variations and host plant specificities

Guan, S.H., Chen, W.F., Wang, E.T., Lu, Y.L., Yan, X.R., Zhang, X.X., and Chen, W.X. 2008. Mesorhizobium caraganae sp. nov., a novel rhizobial species nodulated with Caragana spp. in China. Int. J. Syst. Evol. Microbiol. 58: 2646 - 2653.

Hensley D.L., and Carpenter P.L. 1979. The effect of temperature on $\mathrm{N}_{2}$ fixation $\left(\mathrm{C}_{2} \mathrm{H}_{2}\right.$ reduction) by nodules of legume and actinomycete-nodulated woody species. Bot. Gaz. 140: 558-564.

Hill, J. E., Penny, S. L., Crowell, K. G., Goh, S. H and Hemmingsen, S. M. 2004. cpnDB: A Chaperonin Sequence Database. Genome Res. 14:1669-1675.

Hill, J. E., Hemmingsen, S. M., Goldade, B. G., Dumonceaux, T. J., Klassen, J., Zijlstra, R. T., Goh, S. H., and Van Kessel, A. G. 2005 (a). Comparison of ileum microflora of pigs fed corn-, wheat-, or barley-based diets by chaperonin-60 sequencing and quantitative PCR. Appl. Environ.Microbiol. 71: 867-875.

Hill, J.E., Town, J.R., and Hemmingsen, S.M. 2005 (b). Improved template representation in cpn60 polymerase chain reaction (PCR) product libraries generated from complex templates by application of a specific mixture of PCR primers. Environ. Microbiol. 8: 741-746.

Hoagland, D.R. and Arnon, D.I. 1950. The water culture method for growing plants without soil. California Agricultural Experimental Station Circular. No. 347. 
Jarvis, B.D.W., Pankhurst, C.E., and Patel, J.J. 1982. Rhizobium loti, a new species of

$404 \quad$ legume root nodule bacteria. Int. J. Syst. Bact. 32: 378-380.

405 Jarvis, B.D.W., Van Berkum, P., Chen, W.X., Nour, S.M., Fernandez, M.P., Cleyet-

406 Marel, J.C., and Gillis, M. 1997. Transfer of Rhizobium loti, Rhizobium huakuii,

$407 \quad$ Rhizobium ciceri, Rhizobium mediterraneum, and Rhizobium tianshanense to

408 Mesorhizobium gen. nov. Int. J. Syst. Bact. 47: 895-898.

409 Jensen, H.L. 1967. Mutual host plant relationships in two groups of legume root nodule

$410 \quad$ bacteria (Rhizobium spp). Arch. Mikrobiol. 59: 174-179.

411 Links, M.G., Dumonceaux T.J., Hemmingsen S.M., and Hill J.E. 2012. The chaperonin-

41260 universal target is a barcode for bacteria that enables de novo assembly of

413 metagenomic sequence data. PLoS One.;7(11):e49755.

414 Lund, P. A. 2009. Multiple chaperonins in bacteria--why so many? FEMS Microbiol.

$415 \quad$ Rev. 33: 785-800.

416 Moukoumi, J., Farrell, R.E., Van Rees, K.J.C., Hynes, R.K., Bélanger, N. 2012. Growth

417 and Nitrogen dynamics of juvenile short rotation intensive cultures of pure and

418 mixed Salix miyabeana and Caragana arborescens. Bioenergy Research 5: 719-

$419 \quad 732$.

420 Okubo, T., Tsukui, T., plus 46 others. 2012. Complete genome sequence of

$421 \quad$ Bradyrhizobium sp. S23321: insights into symbiosis evolution in soil oligotrophs.

422 Microbes and environments. JSME 27: 306-315.

423 Ralser, M., Querfurth, R., Warnatz, H.J., Lehrach, H., Yaspo, M.L., and Krobitsch, S.

424 2006. An efficient and economic enhancer mix for PCR. Biochem Biophys Res

$425 \quad$ Commun. 347: 747-51. 
426 Richter, M. \& Rossello-Mora, R. 2009. Shifting the genomic gold standard for the prokaryotic species definition. Proc. Nat. Acad. Sci. USA. 106: 19126-19131.

428 Sahgal, M., and Johri, B.N. 2006. Taxonomy of rhizobia: Current status. Current Science $42990: 486-487$.

430 Saitou, N. and Nei, M. 1987. The neighbor-joining method: A new method for reconstructing phylogenetic trees. Mol. Biol. Evol. 4: 406-425.

432 Shimoda, Y., Shinpo, S., Kohara, M., Nakamura, Y., Tabata, S., Sato, S. 2008. A large reports on genes and genomes 15: 13-23

436 Tamura, K., Dudley, J., Nei, M., and Kumar, S. 2007. MEGA4: Molecular Evolutionary Genetics Analysis (MEGA) software version 4.0. Mol. Biol. Evol. 24:1596-1599.

Thompson, J. D., Higgins, D. G. and Gibson, T. J. 1994. CLUSTAL W: improving the sensitivity of progressive multiple sequence alignment through sequence weighting, position-specific gap penalties and weight matrix choice. Nucleic Acids Res. 22: 4673-4680.

Turner S. L., Zhang X.X., Li, F.D., Young, J.P. 2002. What does a bacterial genome 2011. Predicting relatedness of bacterial genomes using the chaperonin-60 universal target (cpn60 UT): Application to Thermoanaerobacter species. Syst. Appl. Microbiol. 34: 171-179. 
449 Vincent, J.M. 1970. A practical manual for the study of root-nodule bacteria,

450 International Biological Program Handbook No. 15, Blackwell Scientific

451 Publications Ltd., Oxford, UK.

452 Vlassak, K., Paul, E., and Harris, R. 1973. Assessment of biological nitrogen fixation in 453 grassland and associated sites. Plant Soil 38: 637-649.

454 Wallington, E. J. and Lund, P. A. 1994. Rhizobium leguminosarum contains multiple 455 chaperonin (cpn60) genes. Microbiology 140: 113-122.

456 Weaver, R.W. and Frederick, L.R. 1982. Rhizobium. In Methods of Soil Analysis, Part 2.

457 Chemical and Microbiological properties - Agronomy Monograph No. 9, Madison, $458 \quad$ WI, USA. pp 1043-1070.

459 Willems, A., Hoste, B., Tang, J., Janssens, D., and Gillis, M. 2001. Differences between 460 subcultures of the Mesorhizobium loti type strain from different culture collections. $461 \quad$ Syst. Appl. Microbiol. 24: 549-553.

462 Wills, B.J. 1982. Rhizobial inoculation of Siberian pea-shrub (Caragana arborescens 463 Lamb.) for semi-arid revegetation. New Zeal. J. Exp. Agr. 10: 353-354.

464 Yan, X.R., Chen, W.F., Fu, J.F., Lu, Y.L., Xue, C.Y., Sui, X.H., Li, Y., Wang, E.T., and 465 Chen, W.X. 2007. Mesorhizobium spp. are the main microsymbionts of Caragana 466 spp. grown in Liaoning Province of China. FEMS Microbiol. Lett. 271: 265-273. 467 Zeigler, D. R. 2003. Gene sequences useful for predicting relatedness of whole genomes 468 in bacteria. Int. J. Syst. Evol. Microbiol. 53, 1893-1900. 
Figure 1. Phylogenetic tree of Mesorhizobium and related species based on a gene fragment

472 corresponding to nucleotides 11-536 of the E. coli $16 \mathrm{~S}$ rRNA-encoding gene. Strains are identified

473 by their GenBank accession numbers (in parentheses). The percentage of 500 replicate trees in

474 which the taxa clustered together is shown next to the corresponding nodes.

475 Figure 2. Phylogenetic analysis of the recA sequences of Mesorhizobium isolates from this report, 476 placed in the context of the isolates reported by Chen et al (2008) and of selected reference strains.

477 Sequences were all trimmed to the same length ( $426 \mathrm{bp}$ ) prior to alignment. The percentage of 500

478 replicate trees in which the taxa clustered together is shown next to the branches. 


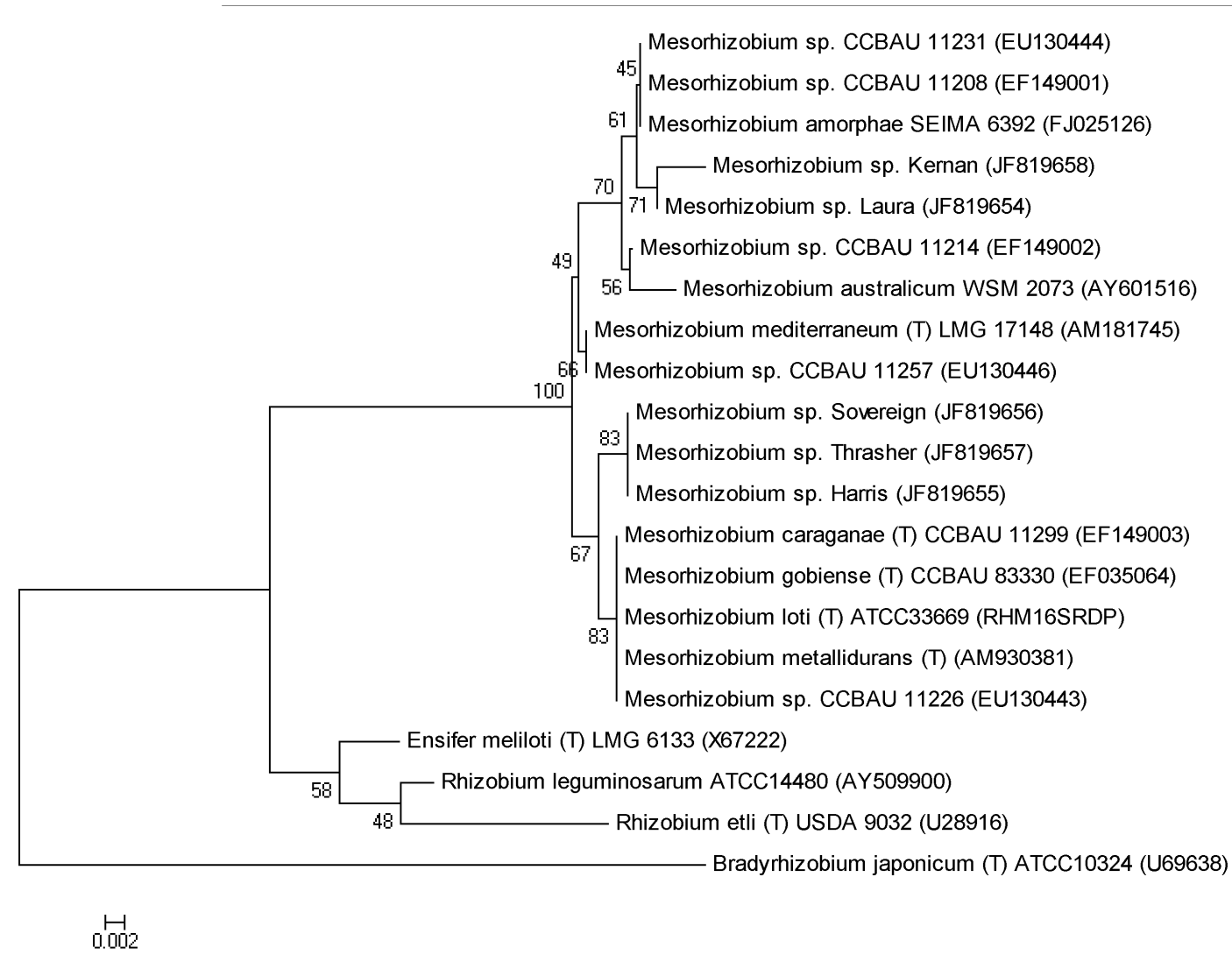

\section{$480 \quad$ Figure 1.}




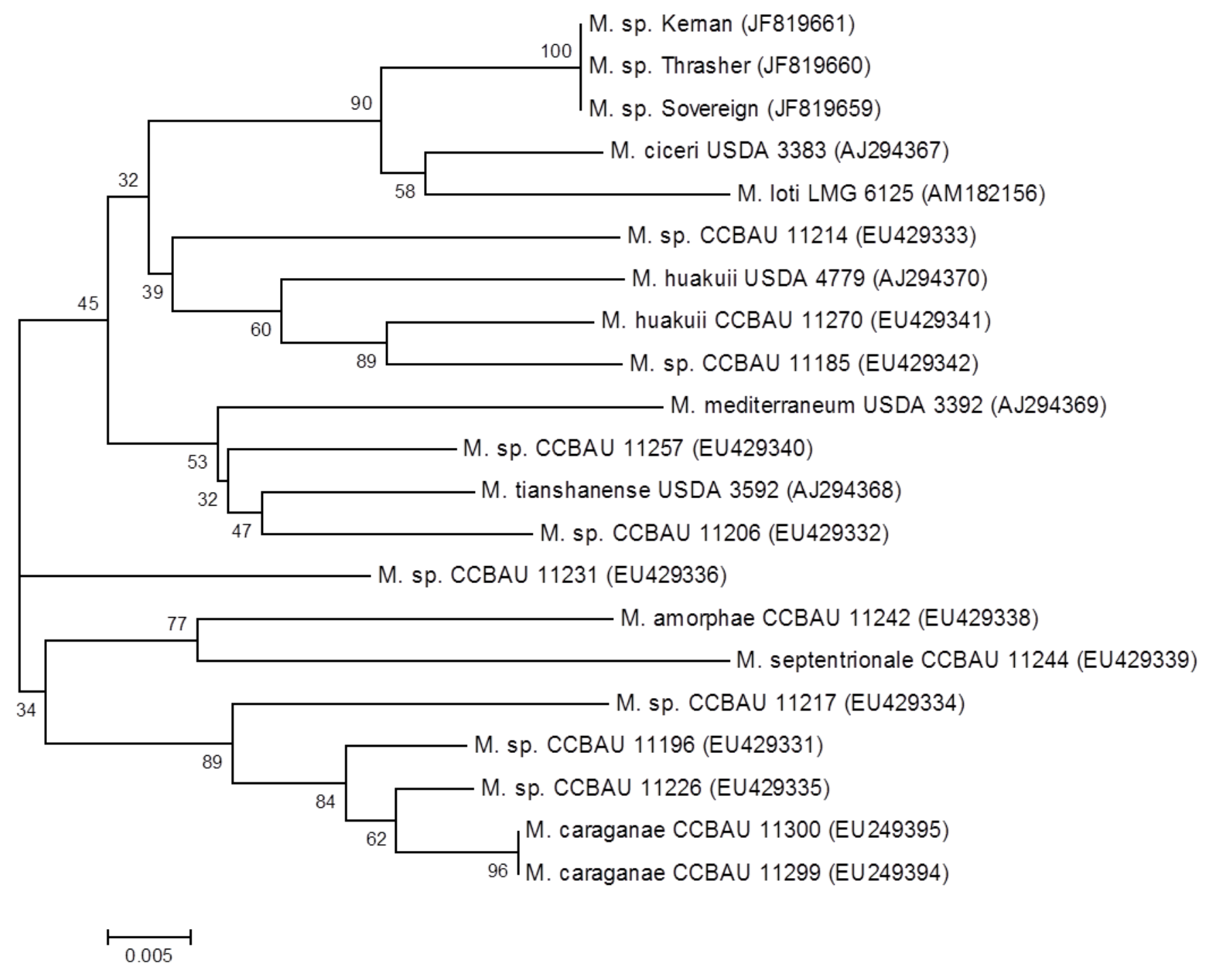

481

482

483 Figure 2.

484

485

486

487

488

489

490 
491 Table 1. Generation times (g) of Rhizobaceae isolates used in this study.

\begin{tabular}{lcc}
\hline Strain & $\mathrm{g}$ (hours) & $\mathrm{SE}$ \\
\hline Mesorhizobium loti Laura & 5.68 & 0.16 \\
Mesorhizobium loti Harris & 6.84 & 0.51 \\
Mesorhizobium loti Sovereign & 7.16 & 0.36 \\
Mesorhizobium loti Thrasher & 6.62 & 0.25 \\
Mesorhizobium loti Kernan & 5.76 & 0.19 \\
Sinorhizobium melioti BALSAC & 3.45 & 0.72 \\
Bradyrhizobium japonicium USDA 110 & 13.86 & 2.08 \\
Rhizobium leguminosarum NRG457 & 4.44 & 0.08 \\
Rhizobium tropici 899 & & 0.70 \\
Mesorhizobium amorpheae & 3.19 & 0.86
\end{tabular}

492 Generation times determined in Yeast extract-mannitol broth, $23^{\circ} \mathrm{C}$, shaking at $150 \mathrm{rpm}$; see 493 materials and methods for additional details. ${ }^{1}$ CIAT899. 
495 Table 2. Percent N, C and $\mathrm{N}_{2}$ derived from the atmosphere from caragana leaves grown from seeds

496 in Hoaglands nitrogen-free media with and without Mesorhizobium isolates.

497

\begin{tabular}{lccc}
\hline \multicolumn{1}{c}{ Treatment } & $\% \mathbf{N}$ & $\% \mathbf{C}$ & $\begin{array}{c}\text { \% } \mathbf{~ N}_{2} \text { derived from } \\
\text { atmosphere }\end{array}$ \\
\hline Non-inoculated & $0.6 \pm 0.1$ & $13.8 \pm 2.9$ & 0 \\
Mesorhhizobium sp Laura & $3.9 \pm 0.3$ & $44.5 \pm 0.7$ & $83.0 \pm 2.1$ \\
Mesorhizobium sp Harris & $2.8 \pm 0.4$ & $44.8 \pm 0.4$ & $78.5 \pm 4.5$ \\
Mesorhizobium sp Sovereign & $2.6 \pm 0.4$ & $44.1 \pm 0.8$ & $76.6 \pm 5.5$ \\
Mesorhizobium sp Thrasher & $2.9 \pm 0.1$ & $44.5 \pm 0.2$ & $80.1 \pm 1.0$ \\
Mesorhizobium sp Kernan & 3.2 & 45.2 & 80.0 \\
\hline
\end{tabular}

498

499 Data represent the mean of 3 reps, 2 for the non-inoculated \pm the standard error and 1 for

500 Mesorhizobium sp. Kernan.

501 
Table 3. Determination of ANIm, ANIb, and Tetra scores using JSpecies along with corresponding genomic sequence identity predictions based on the cpn60 UT and a one-gene recA-based model. Only representative results are shown for the 5 complete M. loti genomes (MAFF303099, WSM1293, R88b, NAP2037, and R7A) that were examined.

\begin{tabular}{|c|c|c|c|c|c|c|c|}
\hline \multirow[b]{2}{*}{ genome } & \multirow[b]{2}{*}{ target genome } & \multicolumn{4}{|c|}{ analysis by JSpecies ${ }^{1}$} & \multicolumn{2}{|c|}{ cpn60 UT sequence identity } \\
\hline & & ANIm & ANIb & Tetra & conclusion & highest & lowest \\
\hline M. loti MAFF303099 (5) & M.australicum WSM 2073 (3) & 88.26 & 86.77 & 0.99708 & different spp & 0.95 & 0.75 \\
\hline M. loti MAFF303099 (5) & M. ciceri bv. biserrulae (4) & 87.82 & 85.82 & 0.99828 & different spp & 0.96 & 0.76 \\
\hline M. loti MAFF303099 (5) & M. opportunistum (4) & 89.12 & 87.84 & 0.99813 & different spp & 0.96 & 0.74 \\
\hline M. loti MAFF303099 (5) & Mesorhizobium sp. BNC1 (2) & 82.78 & 71.83 & 0.89382 & different spp & 0.83 & 0.74 \\
\hline M. loti MAFF303099 (5) & M. loti R7A (4) & 98.53 & 98.46 & 0.99936 & same spp. & 0.99 & 0.76 \\
\hline M. loti MAFF303099 (5) & M. loti WSM1293 (3) & 87.89 & 85.83 & 0.99845 & different spp & 0.94 & 0.76 \\
\hline M. loti WSM1293 (3) & M. loti R88b (3) & 87.77 & 85.86 & 0.99781 & different spp & 0.95 & 0.76 \\
\hline M.australicum WSM 2073 (3) & M. ciceri bv. biserrulae (4) & 88.57 & 86.92 & 0.9966 & different spp & 1.00 & 0.77 \\
\hline M.australicum WSM 2073 (3) & M. opportunistum (4) & 89.35 & 88.2 & 0.99853 & different spp & 1.00 & 0.76 \\
\hline M.australicum WSM 2073 (3) & Mesorhizobium sp. BNC1 (2) & 83.12 & 71.64 & 0.89391 & different spp & 0.85 & 0.75 \\
\hline M. ciceri bv. biserrulae (4) & M. opportunistum (4) & 89.34 & 89.89 & 0.99834 & different spp & 1.00 & 0.76 \\
\hline M. ciceri bv. biserrulae (4) & Mesorhizobium sp. BNC1 (2) & 82.9 & 71.5 & 0.89034 & different spp & 0.86 & 0.76 \\
\hline Mesorhizobium sp. BNC1 (2) & M. opportunistum (4) & 82.96 & 71.83 & 0.89066 & different spp & 0.86 & 0.76 \\
\hline
\end{tabular}

\footnotetext{
${ }^{1}$ JSpecies was used to determine ANIm, ANIb, and Tetra values as described by Richter and Rossello-Mora (2009). An ANIm/ANIb of 95\% with Tetra >0.99
} is used to designate two strains as the same species. 
506 Table 4. cpnDB nearest neighbor for each copy of cpn60 analyzed for all isolates. cpn60 copies are numbered arbitrarily. Matches are

507 identified by their cpnDB ID numbers and, if applicable, by their GenBank accession numbers.

\begin{tabular}{llr}
\hline Isolate & cpnDB nearest neighbor & fasta \%ID \\
\hline Mesorhizobium spp. Laura & & 92.4 \\
cpn60-1 & b4797 NC_002678 Mesorhizobium loti MAFF303099 & 87.4 \\
cpn60-2 & b19969 AGSN01000124 Mesorhizobium amorphae CCNWGS0123 & 87.2 \\
cpn60-3 & b1085 NC_002679 Mesorhizobium loti MAFF303099 \\
cpn60-4 & b1085 NC_002679 Mesorhizobium loti MAFF303099 & 94.1 \\
cpn60-5 & b19969 AGSN01000124 Mesorhizobium amorphae CCNWGS0123 & 96.4 \\
Mesorhizobium spp. Harris & & \\
cpn60-1 & b19971 AGSN01000157 Mesorhizobium amorphae CCNWGS0123 & 92.6 \\
cpn60-2 & v12449 Mesorhizobium amorphae DSM 21831 & 89.9 \\
cpn60-3 & b1085 NC_002679 Mesorhizobium loti MAFF303099 & 94.1 \\
cpn60-4 & b18426 CP002447 Mesorhizobium ciceri biovar biserrulae & 98.7 \\
cpn60-5 & b19967 AGSN01000015 Mesorhizobium amorphae CCNWGS0123 & 86.3 \\
Mesorhizobium spp. Sovereign & & \\
cpn60-1 & b19971 AGSN01000157 Mesorhizobium amorphae CCNWGS0123 & 92.6 \\
cpn60-2 & b1085 NC_002679 Mesorhizobium loti MAFF303099 \\
cpn60-3 & b18426 CP002447 Mesorhizobium ciceri biovar biserrulae & 94 \\
Mesorhizobium spp. Thrasher & & 98.7 \\
cpn60-1 & b19971 AGSN01000157 Mesorhizobium amorphae CCNWGS0123 & 87.5 \\
cpn60-2 & b1085 NC_002679 Mesorhizobium loti MAFF303099 \\
cpn60-3 & 19971 AGSN01000157 Mesorhizobium amorphae CCNWGS0123 & 92.6 \\
cpn60-4 & v12449 Mesorhizobium amorphae DSM 21831 & 89.9 \\
cpn60-5 & b18426 CP002447 Mesorhizobium ciceri biovar biserrulae & 98.7 \\
cpn60-6 & b18427 CP002447 Mesorhizobium ciceri biovar biserrulae & 95.3 \\
cpn60-7 & v12449 Mesorhizobium amorphae DSM 21831 & 96 \\
Mesorhizobium spp. Kernan &
\end{tabular}

Mesorhizobium spp. Kernan 
